\title{
MODELING AND SIMULATION OF CONDENSED SULFUR IN CATALYTIC BEDS OF CLAUS PROCESS: RAPID ESTIMATION
}

\author{
R. Abedini*, ${ }^{* 1}$ M. Koolivand Salooki ${ }^{2}$, S. Ghasemian ${ }^{3}$ \\ ${ }^{1}$ Department of Chemical Engineering, Faculty of Chemical Engineering, Tarbiat Modares University, Tehran, Iran \\ ${ }^{2}$ National Iranian South Oil Company (NISOC), Ahwaz, Iran \\ ${ }^{3}$ Department of Food Science and Technology, Ferdowsi University of Mashhad, Mashhad, Iran
}

Received 23 July 2010; received in revised form 8 November 2010

\begin{abstract}
The Claus process has been known and used in the industry for over 100 years. It involves thermal oxidation of hydrogen sulfide and its reaction with sulfur dioxide to form sulfur and water vapor. This process is equilibrium-limited and usually achieves efficiencies in the range of 94-97\%, which have been regarded as acceptable in the past years. First bed operates at the temperature of $573 \mathrm{~K}$, second and third beds operate at $523 \mathrm{~K}$ and $473 \mathrm{~K}$. Outlet of each bed enters the condenser. Operating temperature of each condenser is about $413 \mathrm{~K}$ which sulfur condenses in them. In this study catalytic bed process of sulfur recovery unit has been mathematically modeled and simulated using MATLAB , and then output conditions of compounds has been calculated.
\end{abstract}

Keywords: Sulfur recovery, Claus process, catalytic beds, modeling, simulation

DOI:10.3329/cerb.v14i2.5595

\section{Introduction}

Claus process which is used nowadays is a modern process precedes the one pioneered in 1883 based on the reaction of $\mathrm{H}_{2} \mathrm{~S}$ over a catalyst base with air (oxygen) in shape of sulfur and water [1]. Sulfur recovery refers to the conversion of hydrogen sulfide $\left(\mathrm{H}_{2} \mathrm{~S}\right)$ to elemental sulfur. Hydrogen sulfide is a byproduct of processing natural gas and refining highsulfur crude oils [2]. approximately 90 to 95 percent of recovered sulfur is produced by the Claus process. The Claus process typically recovers 95 to 97 percent of the hydrogen sulfide feed stream. Clause process briefly described bellow [3].

Hydrogen sulfide, a byproduct of crude oil and natural gas processing, is recovered and converted to elemental sulfur by the Claus process. The process consists of multistage catalytic oxidation of hydrogen sulfide; each catalytic stage consists of a gas reheater, a catalyst chamber, and a condenser. The Claus process involves burning one-third of the $\mathrm{H}_{2} \mathrm{~S}$ with air in a reactor furnace to form Sulfur dioxide $\left(\mathrm{SO}_{2}\right)$ according to the following reaction:

$$
\mathrm{H}_{2} \mathrm{~S}+\frac{3}{2} \mathrm{O}_{2} \rightleftharpoons \mathrm{SO}_{2}+\mathrm{H}_{2} \mathrm{O} ; \Delta H=-560 \mathrm{~kJ} / \mathrm{mol}
$$

The furnace normally operates at combustion chamber temperatures ranging from 980 to $1540^{\circ} \mathrm{C}\left(1800\right.$ to $\left.2800^{\circ} \mathrm{F}\right)$ with pressures rarely higher than $70 \mathrm{kPa}$. Before entering a sulfur condenser, hot gas from the combustion chamber is quenched in a waste heat boiler that generates high to medium pressure steam. About 80 percent of the heat released could be recovered as useful energy. Approximately 65 to 70 percent of the sulfur is recovered. The cooled gases exiting the condenser are then sent to the catalyst beds. The

\footnotetext{
*Corresponding author, Email:r.abedini@modares.ac.ir
}

remaining uncombusted two-thirds of the hydrogen sulfide undergoes Claus reaction (Reacts with $\mathrm{SO}_{2}$ ) to form elemental sulfur as follows:

$$
2 \mathrm{H}_{2} \mathrm{~S}+\mathrm{SO}_{2} \rightleftharpoons \frac{3}{2} \mathrm{~S}_{2}+2 \mathrm{H}_{2} \mathrm{O} ; \Delta H=+47 \mathrm{~kJ} / \mathrm{mol}
$$

The remaining $\mathrm{H}_{2} \mathrm{~S}$, from the Claus furnace, is reacted with the $\mathrm{SO}_{2}$ at lower temperatures (about 470-620 K) over an alumina- or titanium dioxide-based catalyst to make more sulfur:

$$
2 \mathrm{H}_{2} \mathrm{~S}+\mathrm{SO}_{2} \rightleftharpoons \frac{3}{8} \mathrm{~S}_{2}+2 \mathrm{H}_{2} \mathrm{O} ; \Delta H=-108 \mathrm{~kJ} / \mathrm{mol}
$$

On average, about $70 \%$ of $\mathrm{H}_{2} \mathrm{~S}$ and $\mathrm{SO}_{2}$ will react via $\mathrm{Re}$ action (III). Note that in the catalytic stage mostly $\mathrm{S}_{8}$ is produced, which is an exothermic reaction whereas in the thermal stage $S_{2}$ is the major product and the reaction is endothermic. Other allotropes of sulfur may also be present in smaller quantities. The overall reaction for the entire process is:

$$
3 \mathrm{H}_{2} \mathrm{~S}+1 \cdot 5 \mathrm{O}_{2} \rightleftharpoons \frac{3}{n} \mathrm{~S}_{\mathrm{n}}+3 \mathrm{H}_{2} \mathrm{O} ; \Delta H=-626 \mathrm{~kJ} / \mathrm{mol}
$$

A typical arrangement for the Claus sulfur recovery process is shown in Figure 1.

Because this reaction represents an equilibrium chemical reaction, it is not possible for a Claus plant to convert all the incoming sulfur compounds to elemental sulfur. Therefore, 2 or more stages are used in series to recover the sulfur. Each catalytic stage can recover half to two-thirds of the incoming sulfur. The number of catalytic stages depends upon the level of conversion desired. It is estimated that 95 to 97 percent overall recoveries can be achieved depending on the number of catalytic reaction stages and the type of reheating method used. A schematic of the process flow diagram along with approximate gas temperatures is shown in Figure 2.

(C)2010 Bangladesh Uni. of Engg. \& Tech. 


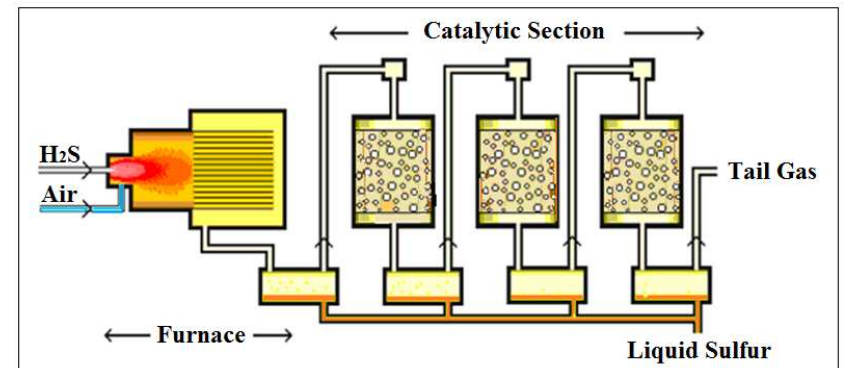

Figure 1: Typical arrangement of a Claus unit [3]

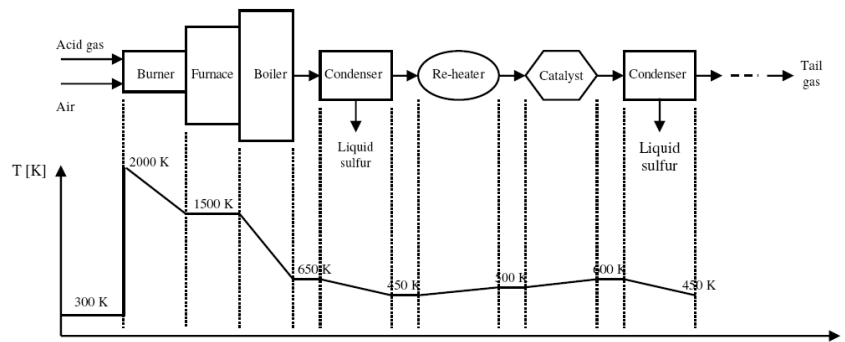

Figure 2: Flow diagram of a typical Claus process [3]

High-pressure steam (40 atm) is generated in the boiler stage and low-pressure steam (3-4 atm) is produced in the condensers. A total of two to four catalytic stages are typically used in order to maximize efficiency.

The Claus process is equilibrium-limited. In the furnace stage the $\mathrm{SO}_{2}$ produced from the combustion process ( $\mathrm{Re}$ action (I)) recombines with $\mathrm{H}_{2} \mathrm{~S}$ in an endothermic reaction to form $\mathrm{S}_{2}$ (Reaction (II)). Adequate residence time has to be provided in order to allow this reaction, responsible for $60-70 \%$ of sulfur conversion, to reach equilibrium. Since the main Claus Reaction (III) is exothermic, this stage calls for the use of low temperatures in order to shift the equilibrium constant towards higher product yields. The low temperatures, however, lead to decreased reaction rates, hence the need for a catalyst. The law of mass action for the Claus reaction is as follows:

$$
K_{P}(T)=\frac{P_{\mathrm{H}_{2} \mathrm{O}}^{2} \times P_{\mathrm{S}_{8}}^{\frac{3}{8}}}{P_{\mathrm{H}_{2} \mathrm{~S}}^{2} \times P_{\mathrm{SO}_{2}}}
$$

where, $K_{P}(T)$ is the chemical equilibrium constant $P_{\mathrm{H}_{2} \mathrm{O}}$ and $\mathrm{P}_{\mathrm{S}_{8}}$, are partial pressures of the products and $P_{\mathrm{H}_{2} \mathrm{~S}}, P_{\mathrm{H}_{2} \mathrm{O}}$ are partial pressures of the reactants. This equation illustrates the nature of equilibrium limitations involved in the Claus process; decreasing the process temperature can increase the equilibrium constant and thus increase conversion, but the lower limit of this temperature and hence the upper limit of equilibrium conversion is set by the condensation temperature of sulfur [3-9].

\section{Modeling of Catalytic Beds}

Modeling of this process consists of three parts which are Mass balance, Energy balance and Condenser formulation. In a case of Molar flow and Energy balance we used the rate formula of reaction II. Kinetic reaction of (II) in the temperature of 200 and $300^{\circ} \mathrm{C}$ is as follow [8]. Because all the three catalytic beds operate at same temperature range this formula seems to be correct:

$$
r=K_{1}(T) P_{\mathrm{H}_{2} \mathrm{~S}} P_{\mathrm{SO}_{2}}^{0.25}-K_{2}(T) P_{\mathrm{H}_{2} \mathrm{O}}
$$

In the above equation if we put $P_{i}=C_{i} R T$ then we have:

$$
r=K_{1}(T)(R T)^{1.25} C_{\mathrm{H}_{2} \mathrm{~S}} C_{\mathrm{SO}_{2}}^{0.25}-K_{2}(T)(R T) C_{\mathrm{H}_{2} \mathrm{O}}
$$

$K_{1}$ and $K_{2}$ are defined as bellow:

$$
\begin{aligned}
& K_{1}=K_{10} \exp \left(-\frac{E_{1}}{R T}\right) \\
& K_{2}=K_{20} \exp \left(-\frac{E_{2}}{R T}\right)
\end{aligned}
$$

$K_{1}$ and $K_{2}$ are activation energy of reaction in the forward and reverse side. The values of $K_{10}, K_{20}, E_{1}$ and $E_{2}$ are as below:

$K_{10}=15762 \frac{\mathrm{mole}}{\mathrm{m}^{3} \cdot \mathrm{s}}, K_{20}=506 \frac{\mathrm{mole}}{\mathrm{m}^{3} \cdot \mathrm{s}}$

$E_{1}=49.4 \frac{\mathrm{kJ}}{\text { mole }}, E_{2}=89.3 \frac{\mathrm{kJ}}{\text { mole }}$

\subsection{Molar Flow Balance}

We consider catalytic bed as Fig 3; by choosing an element on the bed we write molar flow balance equations:

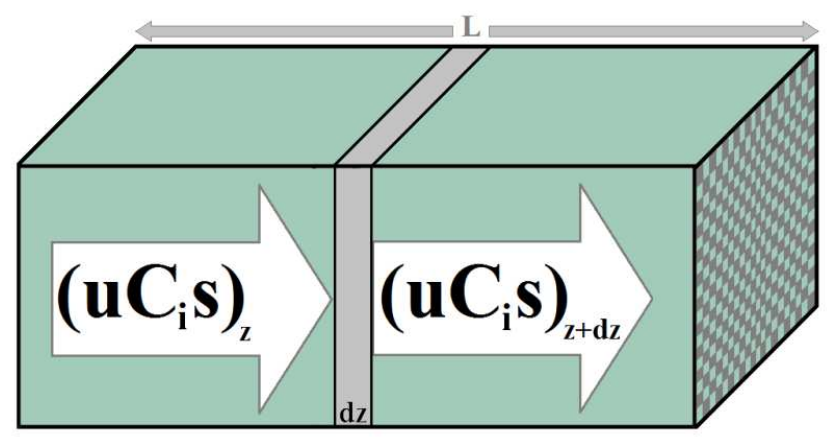

Figure 3: Sample modeled catalytic bed for molar flow balance

$$
\begin{gathered}
\text { Input }- \text { Output }+ \text { Generation }- \text { Consumption }=0 \\
\left(u C_{i} s\right)_{z}-\left(u C_{i} s\right)_{z+d z}+s \frac{1}{v} \frac{d n_{i}}{d t}=0 \\
u \frac{d C_{i}}{d z}+K f\left(C_{i}\right)=0 \\
u \frac{d C_{i}}{d z}+r_{i}=0
\end{gathered}
$$

In above equations $i$ is related to each element of reaction. For solving the Equations 7 to 9, we need the rate of reaction 
of each component. We use rate of reaction of $\mathrm{H} 2 \mathrm{~S}$ as a basis for our calculations. Rate of each component in the reaction has a relation with stokiometric factor of that component in the reaction, so we can calculate the rate of each component in the reaction with respect to rate of $\mathrm{H}_{2} \mathrm{~S}$ then by substitution of Equation (12) in the equation of Eq. (7) to (9) we solve the problem.

$$
\frac{-r\left(\mathrm{H}_{2} \mathrm{~S}\right)}{2}=-r\left(\mathrm{SO}_{2}\right)=\frac{2 r\left(\mathrm{~S}_{2}\right)}{3}=\frac{r\left(\mathrm{H}_{2} \mathrm{O}\right)}{2}
$$

\subsection{Energy balance}

We consider catalytic bed as Figure 4; by choosing an element on the bed and considering input and output energy as $\rho_{i} u c_{p_{i}} T$, then we have:

$$
\begin{gathered}
\text { Input }- \text { Output }+ \text { Generation }- \text { Consumption }=0 \\
\frac{d}{d z}\left[\rho_{i} u C_{P i} T\right]=(-\Delta H) r_{i}
\end{gathered}
$$

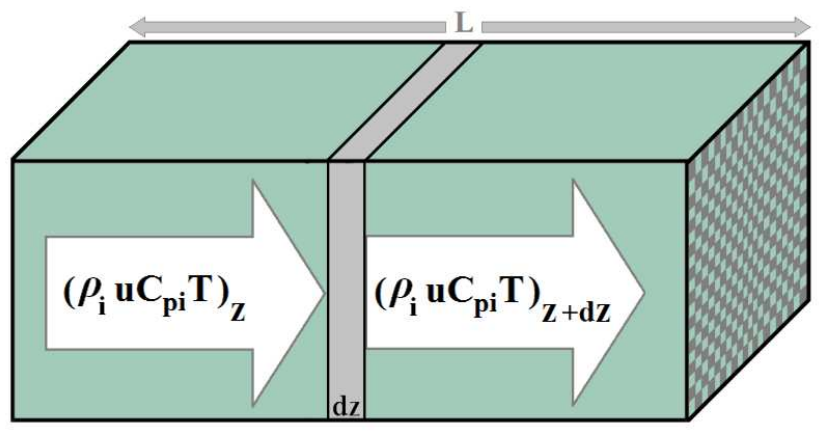

Figure 4: Sample modeled catalytic bed for energy balance

\subsection{Condenser formulation}

Gas composition of inlet gas to the condenser contains a large amount of sulfur; because the condenser temperature is about $140^{\circ} \mathrm{C}$ so the produced sulfur will be condensed and separated. The most important point in sulfur recovery in the catalytic bed is that all the sulfur is not totally separated in each bed, and a portion of the sulfur will enter the next bed, so the condensed sulfur in second and third bed is equal to the sum of produced sulfur of that bed and amount of sulfur that is transferred from the previous bed. Amount of sulfur that is remain in gaseous phase in each condenser and entered to the next bed is calculated from bellow relations:

$$
x_{s} P_{s}^{*}=y_{s} P_{t}
$$

Because the liquid phase in the condenser only contains sulfur so $x_{s}=1 . P_{s}^{*}$ is the saturation pressure of the sulfur and $P_{t}$ is operating pressure.

$$
\begin{gathered}
y_{s}=\frac{P_{s}^{*}}{P_{t}} \\
Y_{s}=\frac{y_{s}}{1-y_{s}}
\end{gathered}
$$

Table 1: Inlet value of each component in the first bed

\begin{tabular}{lrrrr}
\hline Component & $\mathrm{H}_{2} \mathrm{~S}$ & $\mathrm{SO}_{2}$ & $\mathrm{H}_{2} \mathrm{O}$ & $\mathrm{S}_{2}$ \\
\hline Inlet Value $(\mathrm{Kmol} / \mathrm{hr})$ & 2 & 1 & 0 & 0.02 \\
\hline
\end{tabular}

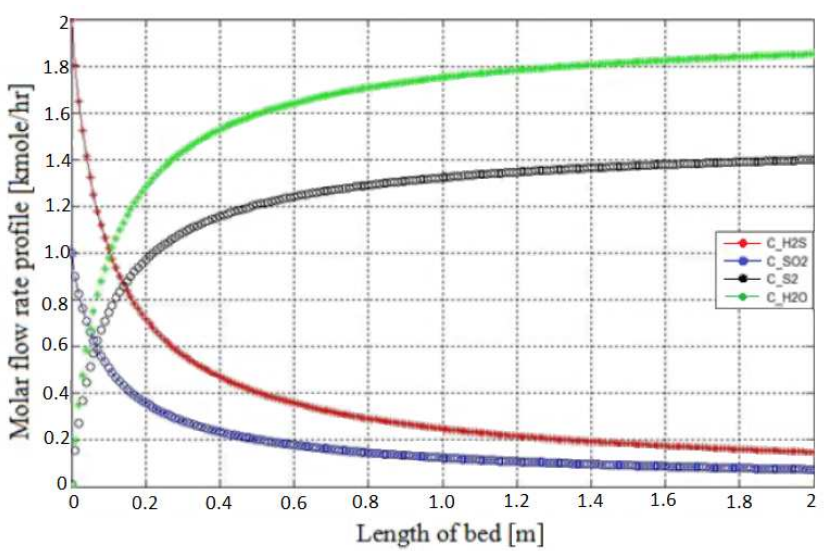

Figure 5: Molar flow rate variation of $\mathrm{H}_{2} \mathrm{O}, \mathrm{S}_{2}, \mathrm{SO}_{2}$, and $\mathrm{H}_{2} \mathrm{~S}$ in the first catalytic bed

$$
G_{s}=G\left(1-y_{s}\right)
$$

$G_{s} Y_{S}$ is the amount of condensed sulfur that is entered to the next bed.

\section{Simulation of Process}

Simulation of this process has been done by using MATLAB software. All the operating condition and all the physical and chemical characteristic of the component have been considered. Physical properties are used as a function of temperature. Amount of inlet sulfur entered to the first bed assumed to be $0.1 \mathrm{kmole} / \mathrm{hr}$. We assume this amount of sulfur is from the furnace.

\section{Results}

Results of simulation with respect to inlet condition of Table 1 are as follow. Also, the length of catalytic bed assumed to be $2 m$; this length is divided to 100 parts.

The variations of mole flow rate of each component in each bed are shown in Figures 5 through 9.

Figures 5 to 9 are obtained by solving molar flow balance equation. As it is clear the composition of $\mathrm{H}_{2} \mathrm{O}$ and $\mathrm{S}_{2}$ will be increased, and the composition of $\mathrm{H}_{2} \mathrm{~S}$ and $\mathrm{SO}_{2}$ will be decreased. Because the variation of compositions in second and third beds are less sensible, variation of compositions of $\mathrm{S}_{2}, \mathrm{H}_{2} \mathrm{~S}, \mathrm{SO}_{2}$ and $\mathrm{H}_{2} \mathrm{O}$ are shown separately. Results of running our program for molar flow balance are shown in Table 2.

Figures of temperature variation in catalytic beds are shown bellow. Figures 10, 11 and 12 are obtained by solving energy balance equation. As it is clear temperature variation in each bed is not sensible and beds work at a constant temperature. 


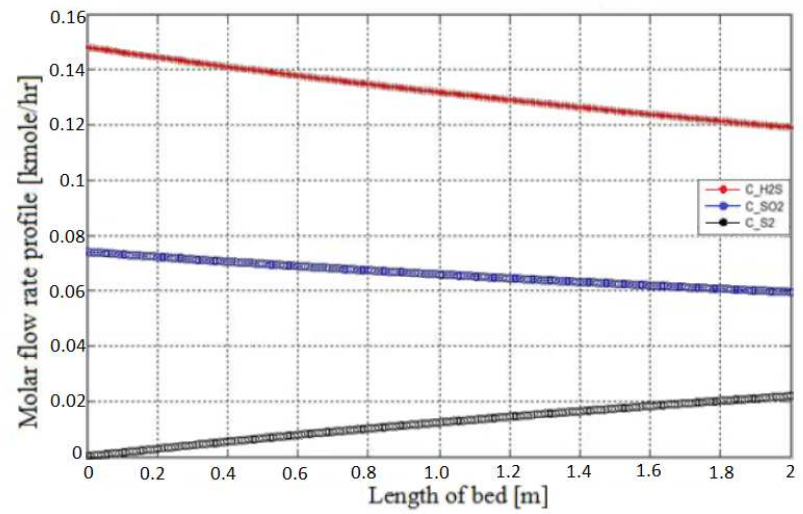

Figure 6: Molar flow rate variation of $\mathrm{S}_{2}, \mathrm{SO}_{2}$, and $\mathrm{H}_{2} \mathrm{~S}$ in the second catalytic bed

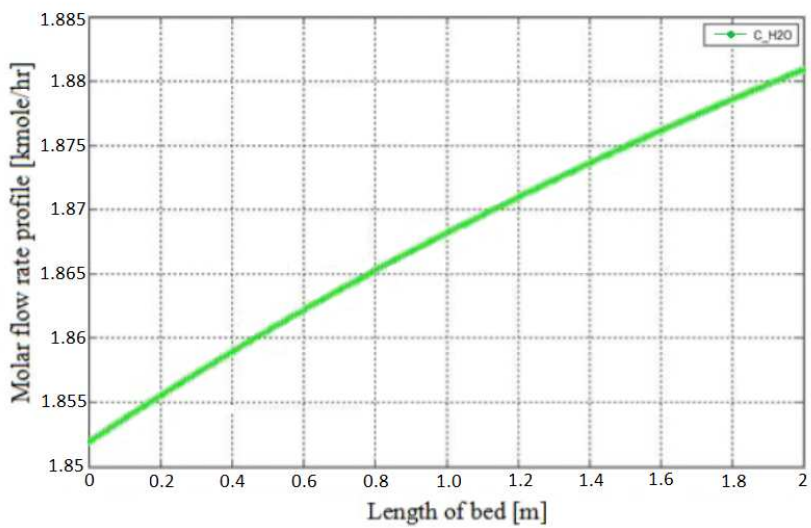

Figure 7: Molar flow rate variation of $\mathrm{H}_{2} \mathrm{O}$ in second catalytic bed

\section{Conclusion}

This research was carried out in a gas refinery plant. In this study, sulfur separation process via catalytic bed modeled and simulated. Modeling has been done with the basis of molar flow and energy balance relations. Inlet flow rate to the first bed has been shown in the Table 1. The length of catalytic bed assumed to be $2 \mathrm{~m}$, this length divided to 100 parts, and in each point of division the mass and energy balance equation have been solved, so molar flow rate of each component in each bed has been calculated. With a simple calculation sulfur mass balance can be shown, so:

Sulfur (Furnace) + Sulfur $\left(\mathrm{SO}_{2}\right)+$ Sulfur $\left(\mathrm{H}_{2} \mathrm{~S}\right)=$ Sulfur (out put) + Sulfur (Condensed)

By solving above relation it is shown that inlet and outlet

Table 2: Flow rate of components in each bed

\begin{tabular}{lrrrr}
\hline Inlet /Outlet Flow Rate of the Beds (Kmol/hr) & $\mathrm{H}_{2} \mathrm{O}$ & $\mathrm{S}_{2}$ & $\mathrm{SO}_{2}$ & $\mathrm{H}_{2} \mathrm{~S}$ \\
\hline Inlet Flow rate to the First bed & 0 & 0.02 & 1 & 2 \\
Outlet Flow rate from the First bed & 1.852 & 1.389 & 0.074 & 0.148 \\
Inlet Flow rate to the Second bed & 1.852 & $9.71 \mathrm{E}-05$ & 0.074 & 0.148 \\
Outlet Flow rate from the Second bed & 1.881 & 0.022 & 0.060 & 0.119 \\
Inlet Flow rate to the Third bed & 1.881 & $6.71 \mathrm{E}-05$ & 0.060 & 0.119 \\
Outlet Flow rate from the Third bed & 1.887 & 0.004 & 0.057 & 0.113 \\
\hline
\end{tabular}

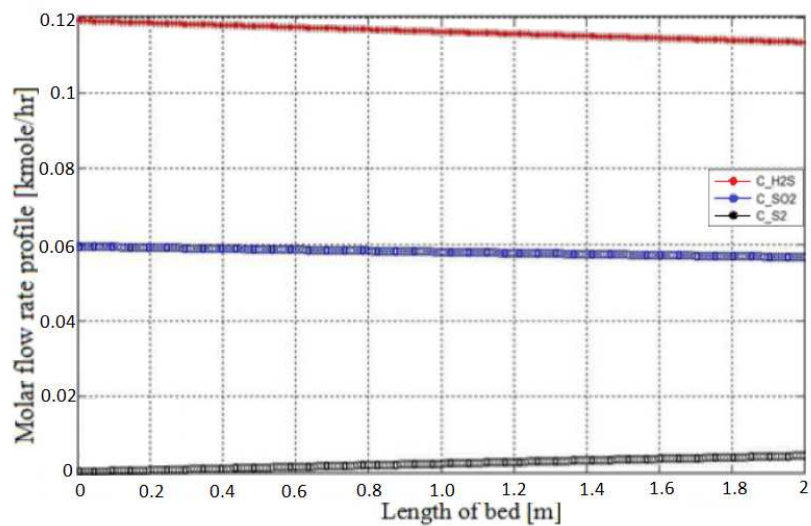

Figure 8: Molar flow rate variation of $\mathrm{H}_{2} \mathrm{~S}, \mathrm{SO}_{2}$ and $\mathrm{S}_{2}$ in the third catalytic bed

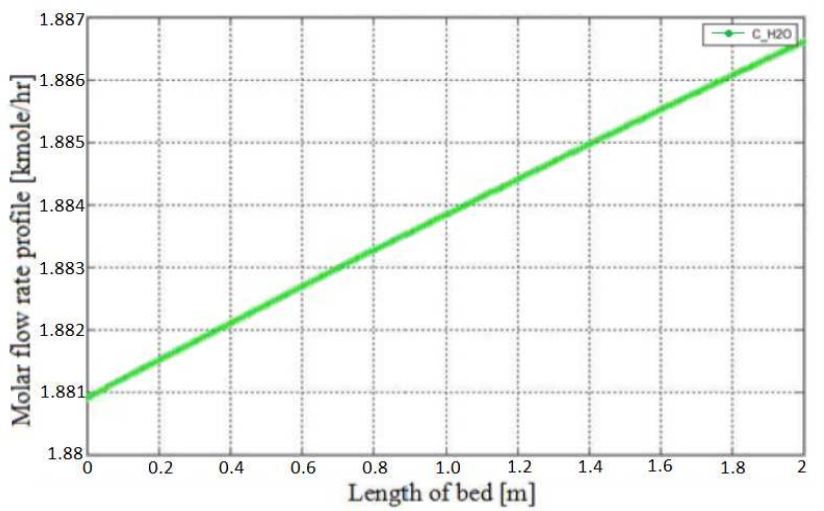

Figure 9: Molar flow rate variation of $\mathrm{H}_{2} \mathrm{O}$ in the third catalytic bed

sulfur is about $3.02 \mathrm{kmol} / \mathrm{hr}$, this amount of sulfur is equal to separation of about $1200 \mathrm{~kg} /$ day sulfur in a sour gas sulfur recovery unit. The molar flow rate and temperature of existence products can be specified by using this model. Also the amount of condensed sulfur in each bed can be calculated simply.

\section{Nomenclature}

$\Delta H \quad$ Reaction Enthalpy Difference $(\mathrm{kJ} / \mathrm{mol})$

$\rho \quad$ Density, $\mathrm{kg} / \mathrm{m}^{3}$

$C_{i} \quad$ Concentration of component $i\left(\mathrm{kmol} / \mathrm{m}^{3}\right)$

$C_{P} \quad$ Specific heat capacity $(\mathrm{kJ} / \mathrm{kg} . \mathrm{K})$

$E_{1} \quad$ Activation energy; forward reaction $(\mathrm{kJ} / \mathrm{mol})$

$E_{1} \quad$ Activation energy; reverse reaction $(\mathrm{kJ} / \mathrm{mol})$

$G \quad$ Gas phase flow rate in condenser $(\mathrm{kmol} / \mathrm{hr})$

$n \quad$ quantity in kmol

$P \quad$ Pressure $(\mathrm{Pa})$

$p_{s} \quad$ Sulfur saturation pressure $(\mathrm{Pa})$

$p_{t} \quad$ Operating pressure $(\mathrm{Pa})$

$R \quad$ Gas constant $\left(\mathrm{Pa} . \mathrm{m}^{3} / \mathrm{kmol} . \mathrm{K}\right)$

$r \quad$ Rate of reaction $\left(\mathrm{kmol} / \mathrm{m}^{3} \mathrm{~s}\right)$

$s \quad$ Cross sectional area of catalyst bed $\left(\mathrm{m}^{2}\right)$

$T \quad$ Temperature $(\mathrm{K})$ 


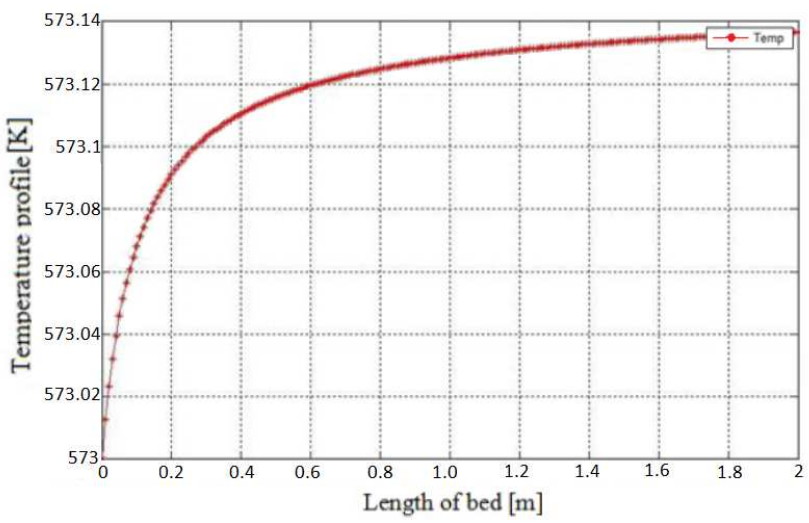

Figure 10: Temperature variation in the first catalytic bed

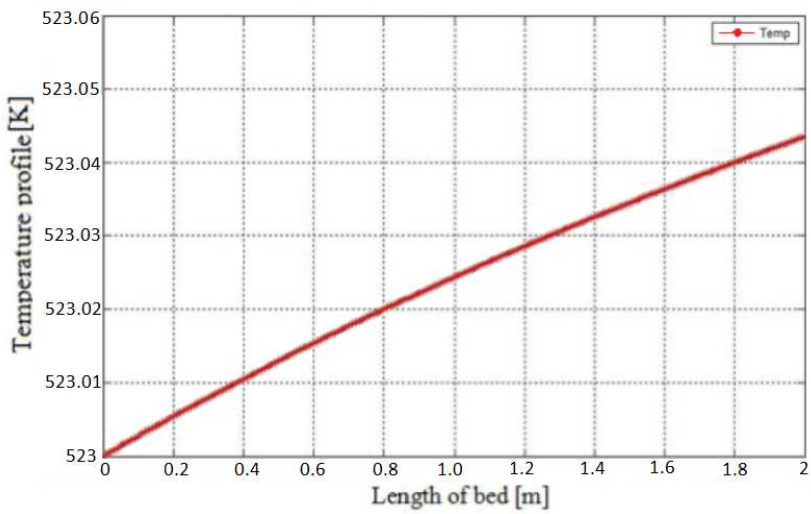

Figure 11: Temperature variation in the second catalytic bed

$t \quad$ Time $(\mathrm{sec})$

$u \quad$ Average flow velocity in bed $(\mathrm{m} / \mathrm{s})$

$v \quad$ Volume of the bed $\mathrm{m}^{3}$

$x_{s} \quad$ Percent of sulfur in liquid phase

$y_{s} \quad$ Percent of sulfur in gas phase

\section{References}

[1] ZareNezhad B and Hosseinpour N, Evaluation of different alternatives for increasing the reaction furnace temperature of Claus SRU by chemical equilibrium calculations, Applied Thermal Engineering, 2008. 28:p. 7. doi:10.1016/j.applthermaleng.2007.06.014

[2] Goar B, Sulfur recovery technology., Energy Progress, 1986. 6(2):pp. 71-75

[3] Sassi M and Gupta A, Sulfur Recovery from Acid Gas Using the Claus Process and High Temperature Air Combustion(HiTAC) Technology, American Journal of Environmental Sciences, 2008. 4(5):pp. 502-511

[4] Monnery W, Svrcek W and Behie L, Modelling the modified claus process reaction furnace and the implications on plant design and recovery, The Canadian Journal of Chemical Engineering, 1993. 71(5):pp. 711-724. doi:10.1002/cjce.5450710509

[5] Levy A and Merryman E, The microstructure of hydrogen sulphide flames, Combustion and Flame, 1965. 9(3):pp. 229-240. doi:10.1016/0010-2180(65) 90089-1

[6] Frenklach M, Lee $\mathrm{J}$, White $\mathrm{J}$ and Gardiner $\mathrm{Jr} \mathrm{W}$, Oxidation of hydrogen sulfide, Combustion and flame, 1981. 41:pp. 1-16. doi:10.1016/0010-2180(81) 90035-3

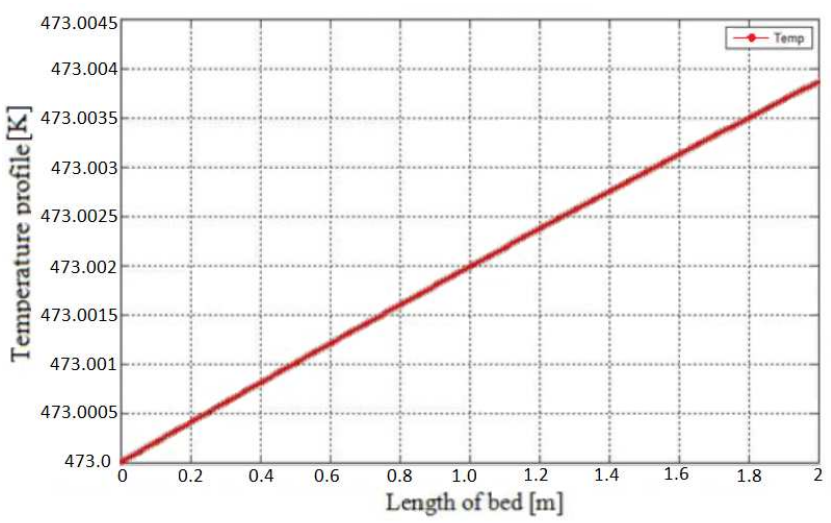

Figure 12: Temperature variation in the third catalytic bed

[7] Tesner PA, Nemirovskii MS and Motyl DN, Kinetics of the thermal decomposition of hydrogen sulide at $800-1200^{\circ} \mathrm{C}$, Kinetika I Kataliz, 1990. 30:pp. 889-892

[8] Elsner M, Menge M, Müller C and Agar D, The Claus process: teaching an old dog new tricks, Catalysis Today, 2003. 79:pp. 487-494. doi:10.1016/S0920-5861(03)00071-3

[9] Monnery W, Hawboldt K, Pollock A and Svrcek W, New experimental data and kinetic rate expression for the Claus reaction, Chemical Engineering Science, 2000. 55(21):pp. 5141-5148. doi:10.1016/S0009-2509(00)00146-9 